\title{
Ocular Autonomic Nerve Function in Lambert-Eaton Myasthenic Syndrome
}

\author{
C. V. CLARK* ${ }^{*}$ J. NEWSOM-DAVIS $\dagger$, M. D. SANDERS \\ London
}

\begin{abstract}
Summary
Autonomic innervation to the eye and ocular adnexae was assessed in seven patients with Lambert-Eaton Myasthenic Syndrome and 50 age-matched control subjects. Pupil responses to light were abnormal in 69\% of LEMS patients, compared with $18 \%$ of the control group. Reflex tear production-a screening test for parasympathetic innervation to the lacrimal gland-was below the accepted normal limit in 69\% of LEMS patients. Parasympathetic and sympathetic denervation hypersensitivity of the iris musculature were individually present in $57 \%$ of LEMS patients, compared with $6 \%$ of control subjects. The association between autonomic dysfunction and Lambert-Eaton Myasthenic Syndrome is discussed.
\end{abstract}

The Lambert-Eaton myasthenic syndrome (LEMS) is characterised by proximal muscle weakness, depressed tendon reflexes and dysautonomia, ${ }^{1}$ and associated specifically with small cell lung carcinoma in about $60 \%$ of cases. ${ }^{2}$ It is an autoimmune disorder ${ }^{3}$ in which IgG antibodies to voltage-gated calcium channels at motor nerve terminals result in impaired release of acetylcholine, and consequent muscle weakness. ${ }^{4-7}$ In small cell cancer-associated cases, the autoantibodies may be triggered by tumour calcium channels. ${ }^{8}$

Assessment of autonomic function has demonstrated both cholinergic dysautonomia $^{9}$ and more generalised dysautonomic function with concomitant involvement of sympathetic nerves. ${ }^{10,11}$ The possible pathogenic role of antibodies in these autonomic disturbances is not known.
Measurement of the responses of the iris musculature to specific stimuli provides a means of assessing autonomic innervation of the eye. Because sympathetic nerve stimulation causes pupillary dilatation, and constriction of the pupil is controlled by the parasympathetic nervous system (via the IIIrd nerve), pupil diameter reflects the balance of autonomic activity in the anterior segment of the eye, and provides an easily-measured, accurate index of autonomic integrity there. Several tests have been developed, enabling detailed assessment of pupillary function. Pupil responses to light may be accurately quantified by measurement of the pupil cycle time. ${ }^{12}$ However pupil cycle time, by definition, is dependent on the complete pupillary reflex arc and, if abnormal, provides no information about where the defect lies. Localisation requires specific tests that investigate

From: The National Hospital of Nervous Diseases, Queen Square, London.

*Present Address: University Ophthalmology Unit, Department of Surgẹry, Eye Pavilion, Chalmers Street, Edinburgh EH3 9HA.

†Present Address: Neurosciences Group, Institute of Molecular Medicine, John Radcliffe Hospital, Oxford OX3 9DU.

Correspondence to: Mr C. Clark MD, ChM, FRCSEd, University Ophthalmology Unit, Department of Surgery, Eye Pavilion, Chalmers Street, Edinburgh EH3 9HA 
Table I Clinical details of LEMS patients

\begin{tabular}{|c|c|c|c|c|c|c|c|c|}
\hline \multirow[b]{2}{*}{ Patient } & \multirow[b]{2}{*}{ Age, Sex } & \multirow{2}{*}{$\begin{array}{c}\text { LEMS } \\
\text { duration } \\
\text { (yrs) }\end{array}$} & \multirow[b]{2}{*}{ Tumour ${ }^{a}$} & \multicolumn{3}{|c|}{ Autonomic symptoms } & \multicolumn{2}{|c|}{$C M A P^{b}$ amplitude } \\
\hline & & & & $\begin{array}{c}\text { Dry } \\
\text { Mouth }\end{array}$ & Constipation & $\begin{array}{c}\text { Sexual } \\
\text { impotence }\end{array}$ & $\begin{array}{l}\text { Initial }^{c} \\
m V\end{array}$ & $\begin{array}{c}\text { Increment } \\
\%\end{array}$ \\
\hline 1 & $53, F$ & 0.1 & ?SCLC & + & + & & 2.6 & 92 \\
\hline 2 & $55, \mathrm{~F}$ & 1.5 & nd & + & + & & 2.6 & 260 \\
\hline 3 & $64, M$ & 4.8 & nd & + & + & & 4.2 & 376 \\
\hline 4 & $63, F$ & 5.3 & SCLC & + & & & 3.2 & 431 \\
\hline 5 & $62, \mathrm{M}$ & 0.1 & SCLC & + & + & + & 5.0 & 160 \\
\hline 6 & $69, \mathrm{M}$ & 3.3 & nd & + & & + & 3.4 & 518 \\
\hline 7 & $28, F$ & 0.3 & nd & + & & & 2.8 & 400 \\
\hline
\end{tabular}

a : SCLC, small cell lung carcinoma; nd, not detected.

b : CMAP, compound muscle action potential.

c : normal $>8.4 \mathrm{mV}$.

$\mathrm{d}$ : percentage increment following 15 secs maximum voluntary contraction; normal $<25 \%$.

individual components of the reflex pathway, such as those that assess denervation hypersensitivity. Parasympathetic denervation hypersensitivity of the iris musculature is demonstrated by excessive pupillary constriction in response to topical $2.5 \%$ methacholine chloride, ${ }^{13,14}$ and sympathetic denervation hypersensitivity by increased pupillary dilatation to topical $0.5 \%$ phenylephrine hydrochloride. ${ }^{15}$

The integrity of the autonomic supply to external ocular structures may be inferred from the reflex production of tears by the lacrimal gland. Secretory innervation to the lacrimal gland passes from the lacrimal (salivatory) nucleus of the facial nerve, via the facial nerve, greater superficial petrosal nerve and sphenopalatine ganglion. ${ }^{16}$

The present study has quantified ocular autonomic nerve function in patients with LEMS by tests based upon pupil responses to light, assessment of denervation hypersensitivity of iris musculature, and assessment of reflex tear production.

\section{Patients and Methods}

After informed consent had been obtained, ocular autonomic nerve function was assessed in seven patients with LEMS (mean age $55.4 \pm 13.7$ years) and 50 age-matched control subjects (mean age $60.7 \pm 18.0$ years). Diagnosis of LEMS was based on typical clinical and electromyographic features; ${ }^{2}$ clinical details are shown in Table I. The control group consisted of patients attending an oph- thalmic casualty department who were subsequently shown to have no ocular abnormality. Subjects were excluded from the study if there was a history either of a medical disorder causing autonomic dysfunction, or of taking 3,4-diaminopyridine or any medication known to affect the autonomic nervous system. Individual eyes were excluded if there was a history of ocular disease, trauma or operation.

A comprehensive ocular examination was performed on all subjects. Ocular autonomic function was assessed by the following methods:

\section{(1) Pupil response to light: Pupil cycle time}

The subject was seated at a slit-lamp in a room with low constant background illumination (20 lux) and fixated straight ahead on a distant object. A horizontal slit-beam of light was set at $6 \times 0.5 \mathrm{~mm}$ and positioned to overlap the inferior margin of the pupil. In response to this stimulus, the pupil initially constricts, then reflexly dilates when the iris blocks the light; return of the afferent impulse causes the pupil to constrict again, and a second cycle commences. One hundred consecutive pupil cycles were timed by stopwatch; the result divided by 100 represents the mean pupil cycle time.

\section{(2) Ocular autonomic denervation}

\section{hypersensitivity}

(a) Parasympathetic nervous system.

Pupil photographs were taken between 
9-11 am under standardised lighting conditions; the subject faced a surface with luminance of 20 apostilbs whilst constant background illumination was maintained. The subject remained seated in the room for five minutes prior to assessment; pupil diameters were then recorded photographically using an ophthalmic head-rest and a scale positioned against the lower eyelid in the perpendicular plane of the iris. The subject fixated at 6 metres, then a photograph at $\times 3$ magnification was taken of both eyes together using a Nikon F camera with Medical Nikkor $120 \mathrm{~mm}$ f4 lens and Kodak ektachrome professional film (ASA 100). One drop of 2.5\% methacholine chloride solution was placed in the conjunctival sac of one eye, and one drop of sterile normal saline solution concurrently placed in the conjunctival sac of the contralateral eye. The eye to be tested was selected randomly. Forty-five minutes later, a second pupil photograph was taken.

(b) Sympathetic nervous system.

One week later, sympathetic denervation hypersensitivity was assessed by the same method. A pupil photograph was taken, then one drop of $0.5 \%$ phenylephrine hydrochloride was placed in the conjunctival sac of the previously untested eye and one drop of sterile normal saline solution placed in the conjunctival sac of the contralateral eye. A second pupil photograph was tàken forty-five minutes later under similar controlled ambient lighting conditions.

The pupil photographs were magnified $(\times 17)$ by projecting the slides on to a white screen at 5 metres. Horizontal pupil diameters were measured directly from the screen to an accuracy of $\pm 0.5 \mathrm{~mm}$; measurements of pupil diameter were therefore accurate to $\pm 0.03 \mathrm{~mm}$, after correction to actual values by comparison with relative magnification of the scale.

Parasympathetic denervation hypersensitivity was expressed as the $2.5 \%$ methacholine ratio:

horizontal pupil diameter 45 minutes post-test

horizontal pupil diameter pre-test

Sympathetic denervation hypersensitivity was expressed as the $0.5 \%$ phenylephrine ratio: horizontal pupil diameter 45 minutes post-test

horizontal pupil diameter pre-test

Measurements of pupil diameters were performed on a double-masked basis, (ie without knowledge of whether the subject was a patient or a control, or whether the pupil was test or control).

\section{(3) Reflex tear production}

Reflex production of tears in patients with LEMS was measured by Schirmer's test. The patient was seated in a room with low, constant background illumination, and a folded strip of Whatman No 41 filter paper $(5 \times 35 \mathrm{~mm})$ was positioned to overlap the inferior lid margin of each eye, according to the standard technique. ${ }^{17}$ The degree of filter paper wetting was measured after five minutes. Normal tear production is defined by wetting of the filter paper by at least $10 \mathrm{~mm}$. Reflex tearing is controlled by the parasympathetic nervous system.

\section{Statistical Analysis}

Comparisons were made between the results of LEMS patients and the control group; significance was assessed by Student's unpaired $t$ test (two way). Results are expressed as mean \pm SEM.

\section{Results}

The individual results of general ocular assessment in seven patients with LEMS are shown in Table II, and the results of ocular autonomic function assessment are shown in Table III.

\section{(i) Pupil cycle time}

Pupil cycling was either absent or sustained for $<100$ consecutive cycles in six of the 13 eyes (46\%) assessed from seven subjects with LEMS, compared with $15 \%$ of eyes in the control group. As pupil cycle time could not be measured in almost half of the eyes from LEMS patients, mean pupil cycle time in the remaining subjects could not be considered representative of the whole group and therefore comparison by Student's $t$ test with the control group was not performed. Results of pupil cycle time assessment in LEMS patients 
Table II Results of General Ocular Assessment in 7 patients with LEMs

\begin{tabular}{|c|c|c|c|c|c|c|c|c|c|c|c|c|c|c|c|c|c|c|c|c|c|c|}
\hline \multirow[t]{2}{*}{ Patient } & \multicolumn{2}{|c|}{$\begin{array}{l}\text { Visual } \\
\text { acuity }\end{array}$} & \multicolumn{2}{|c|}{$E O M$} & \multicolumn{2}{|c|}{$\begin{array}{l}\text { Colour } \\
\text { vision } \\
\text { (Ishihara) }\end{array}$} & \multicolumn{2}{|c|}{$\begin{array}{l}\text { Visual } \\
\text { field }\end{array}$} & \multicolumn{2}{|c|}{$\begin{array}{c}\text { Palpebral } \\
\text { aperture } \\
(\mathrm{mm})\end{array}$} & \multicolumn{2}{|c|}{$\begin{array}{l}\text { Anterior } \\
\text { chamber }\end{array}$} & \multicolumn{2}{|c|}{ Cornea } & \multicolumn{2}{|c|}{$\begin{array}{c}\text { Anterior } \\
\text { chamber } \\
\text { angle }\end{array}$} & \multicolumn{2}{|c|}{$\begin{array}{l}\text { Intraocular } \\
\text { pressure* } \\
(\mathrm{mmHg})\end{array}$} & \multicolumn{2}{|c|}{$\begin{array}{l}\text { Cup:disc } \\
\text { ratio }\end{array}$} & \multicolumn{2}{|c|}{ Retina } \\
\hline & $R$ & $L$ & $R$ & $L$ & $R$ & $L$ & $R$ & $L$ & $R$ & $L$ & $R$ & $L$ & $R$ & $L$ & $R$ & $L$ & $R$ & $L$ & $R$ & $L$ & $R$ & $L$ \\
\hline 1 & $6 / 9$ & $6 / 9$ & Full & Full & $14 / 14$ & $14 / 14$ & Full I & Full & 9 & 9 & $\mathrm{~N}$ & $\mathrm{~N}$ & $\mathrm{~N}$ & $\mathrm{~N}$ & Wide & Wide & 14 & 14 & 0.3 & 0.3 & $\mathrm{~N}$ & $\mathrm{~N}$ \\
\hline 2 & $6 / 6$ & $6 / 6$ & Full & Full & $14 / 14$ & $14 / 14$ & Full I & Full & 10 & $8^{* *}$ & $\mathrm{~N}$ & $\mathrm{~N}$ & $\mathrm{~N}$ & $\mathrm{~N}$ & Wide & Wide & 12 & 12 & 0.4 & 0.3 & $\mathrm{~N}$ & $\mathrm{~N}$ \\
\hline 3 & $6 / 9$ & $6 / 9$ & Full & Full & $14 / 14$ & $14 / 14$ & Full I & Full & 8 & 8 & $\mathrm{~N}$ & $\mathrm{~N}$ & $\mathrm{~N}$ & $\mathrm{~N}$ & Wide & Wide & 23 & 23 & 0.5 & 0.6 & $\mathrm{~N}$ & $\mathrm{~N}$ \\
\hline 4 & $6 / 9$ & $6 / 9$ & Full & Full & $14 / 14$ & $.14 / 14$ & Full I & Full & 11 & 11 & $\mathrm{~N}$ & $\mathrm{~N}$ & $\mathrm{~N}$ & $\mathrm{~N}$ & Wide & Wide & 16 & 15 & 0.3 & 0.3 & $\mathrm{~N}$ & $\mathrm{~N}$ \\
\hline 5 & $6 / 9$ & $6 / 9$ & Full & Full & $14 / 14$ & $14 / 14$ & Full I & Full & 15 & $14^{* *}$ & $\mathrm{~N}$ & $\mathrm{~N}$ & $\mathrm{~N}$ & $\mathrm{~N}$ & Wide & Wide & 14 & 14 & 0.2 & 0.2 & $\mathrm{~N}$ & $\mathrm{~N}$ \\
\hline 6 & $6 / 5$ & $6 / 18$ & Full & Full & $4 / 14$ & $4 / 14$ & Full & Full & 10 & 10 & $\mathrm{~N}$ & $\mathrm{~N}$ & $\mathrm{~N}$ & $\mathrm{~N}$ & Wide & Wide & 12 & 14 & 0.3 & 0.4 & $\mathrm{~N}$ & $\mathrm{~N}$ \\
\hline 7 & $6 / 5$ & $6 / 5$ & $\begin{array}{l}\text { Slow } \\
\text { sacch }\end{array}$ & ades & $14 / 14$ & $14 /, 14$ & Full & Full & 8 & 8 & $\mathbf{N}$ & $\mathrm{N}$ & $\mathrm{N}$ & $\mathrm{N}$ & Wide & Wide & 16 & 16 & 0.2 & 0.2 & $\mathrm{~N}$ & $\mathrm{~N}$ \\
\hline
\end{tabular}

** Slight ptosis.

$\mathrm{N}=$ Normal, ${ }^{*}$ normal range $10-21 \mathrm{mmHg}$.

were therefore compared with the normal tolerance limit. Age-adjusted normal tolerance intervals have been established for pupil cycle time $;^{12} \log _{10}$ (pupil cycle time) is not significantly age-dependent $(P>0.05)$. The ageadjusted normal tolerance limit, aribitrarily set at the upper 95th percentile of the log normal distribution after regression on age, was applied to the results of LEMS patients and control subjects to determine the proportion of eyes outside the normal limit. Pupil cycle time was higher than the 95 th percentile in three of the 13 eyes from LEMS patients (23\%), compared with $3 \%$ of eyes in the control group. Pupil cycle time was therefore abnormal in $69 \%$ of eyes from LEMS patients (ie $6 / 13,46 \%$ with absence of sustained pupil cycling, and $3 / 13,23 \%$ with significantly prolonged pupil cycle time), compared with $18 \%$ of the control group (Fig. 1).

\section{(ii) Ocular autonomic denervation}

hypersensitivity

(a) Parasympathetic denervation hypersensitivity: $2.5 \%$ methacholine ratio.

Pupillary constriction in response to topical $2.5 \%$ methacholine was significantly greater in patients with LEMS $(0.70 \pm 0.05)$ than in the control group $(0.94 \pm 0.02)(P<0.002)$. There were no significant differences in $2.5 \%$ methacholine ratios between patients with carcinoma-associated LEMS (0.68 \pm 0.09$)$ and non-carcinoma-associated LEMS $(0.71 \pm 0.08)$.

Pupillary responses to $2.5 \%$ methacholine are significantly related to age $(r=0.40$; $P<0.001) .^{14}$ The results of LEMS patients and control subjects were compared with the age-adjusted normal tolerance limit ie the lower 5 th percentile of the log normal distribution after regression on age. By this cri-

Table III Results of Ocular Autonomic Nerve Function in 7 patients with LEMS.

\begin{tabular}{|c|c|c|c|c|c|c|}
\hline \multirow[b]{2}{*}{ Patient } & \multicolumn{2}{|c|}{$\begin{array}{l}\text { Pupil cycle time } \\
\text { (ms) }\end{array}$} & \multirow{2}{*}{$\begin{array}{l}2.5 \% \text { Methacholine } \\
\text { ratio }\end{array}$} & \multirow{2}{*}{$\begin{array}{l}0.5 \% \text { Phenylephrine } \\
\text { ratio }\end{array}$} & \multicolumn{2}{|c|}{$\begin{array}{c}\text { Tear production: } \\
\text { Schirmer's test } \\
(\mathrm{mm})\end{array}$} \\
\hline & $R$ & $L$ & & & $R$ & $L$ \\
\hline 1 & Hippus** & Hippus** & 0.80 & $1.60^{* *}$ & $1+$ & $1+$ \\
\hline 2 & 1138 & $1449^{* *}$ & 0.88 & $1.41^{*}$ & $5+$ & 14 \\
\hline 3 & 903 & 858 & 0.78 & 1.38 & $2+$ & $0+$ \\
\hline 3 & pseudaphake & 888 & $0.74^{*}$ & 1.20 & pseudaphake & 35 \\
\hline 5 & $1402^{* *}$ & $1469^{*}$ & $0.49^{* *}$ & 1.43 & 29 & 23 \\
\hline 6 & Hippus** & Hippus** & $0.54^{* *}$ & $1.74^{* *}$ & $5+$ & $4+$ \\
\hline 7 & Hippus** & Hippus** & $0.64^{* *}$ & $1.41^{* *}$ & $5+$ & $5+$ \\
\hline
\end{tabular}

Significance:

$* \mathrm{p}<0.05$.

** $\mathrm{p}<0.01$.

+ abnormal. 


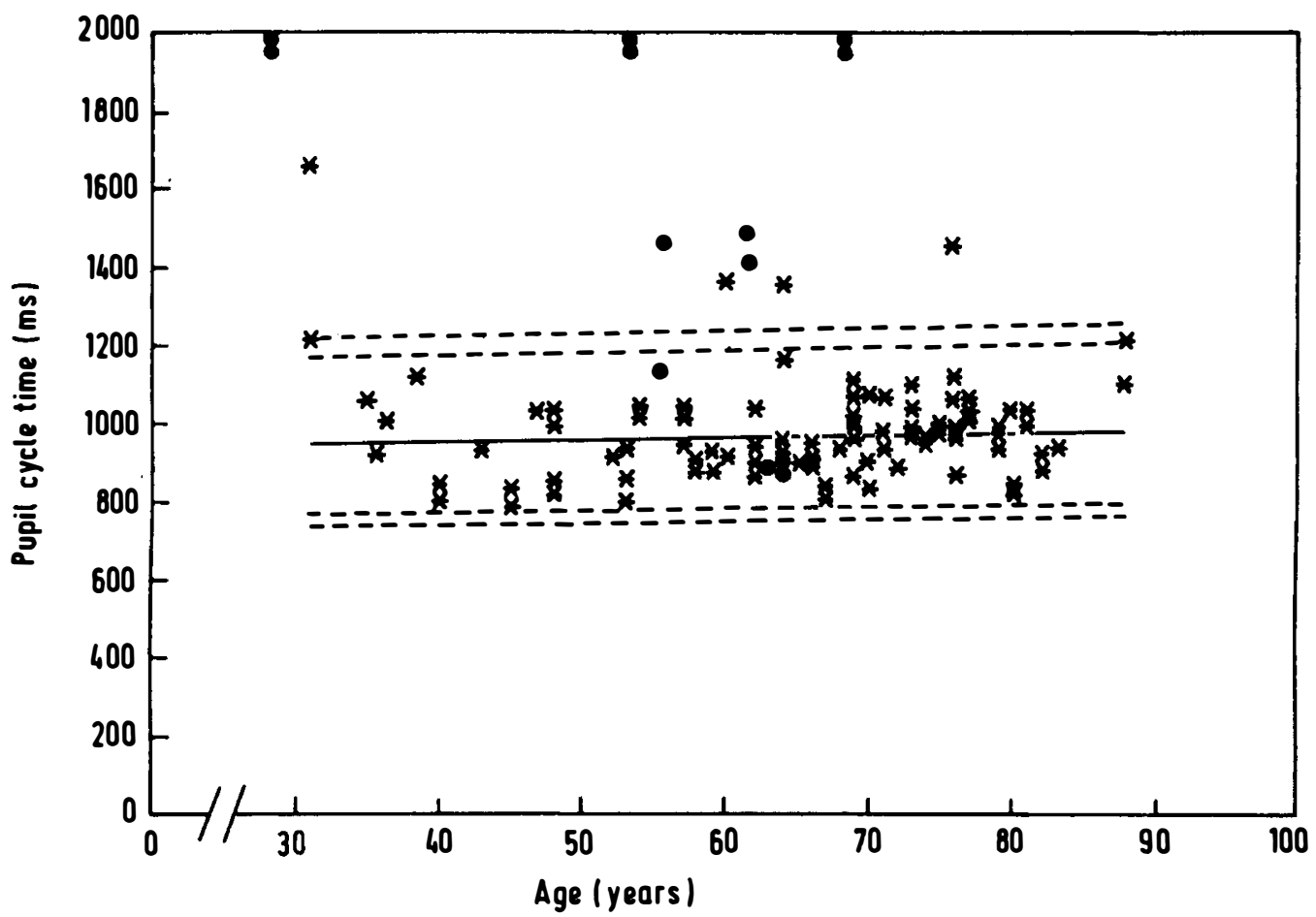

\section{$\bullet=$ LEMS patients \\ * = Control subjects}

Fig. 1. Age-adjusted normal tolerance intervals for pupil cycle time: mean, and the 90th and 95th percentiles of the log normal distribution (hatched line) are shown.

terion, parasympathetic neuropathy was present in four of the seven patients with LEMS (57\%) compared with $6 \%$ of the control group (Fig. 2).

\section{(b) Sympathetic denervation} hypersensitivity: $0.5 \%$ phenylephrine ratio.

Pupillary dilatation in response to topical $0.5 \%$ phenylephrine was significantly higher in LEMS patients $(1.45 \pm 0.06)$ than the control group $(1.19 \pm 0.03)(P<0.01)$. There were no significant differences in $0.5 \%$ phenylephrine ratios between patients with carcinoma-associated LEMS (1.41 \pm 0.12$)$ and non-carcinoma-associated LEMS $(1.48 \pm 0.08)(P<0.05)$.

Pupil responses to $0.5 \%$ phenylephrine are significantly age-dependent $\quad(\mathrm{r}=0.64$; $P<0.001) .{ }^{15}$ The results of LEMS patients and control subjects were compared with the age-adjusted normal tolerance limit ie the upper 95th percentile of the log normal distribution after regression on age. By this criterion, sympathetic neuropathy was present in four of the seven patients with LEMS $(57 \%)$, compared with $6 \%$ of the control group (Fig. 3).

\section{iv. Reflex tear production}

Reflex tear production, measured by Schirmer's test, was abnormal in nine of the 13 eyes tested $(69 \%)$ from patients with LEMS.

\section{Discussion}

The integrity of autonomic innervation to the eye needs to be assessed clinically by noninvasive tests, based upon the response of an effector to a specific autonomic stimulus. The pupil provides a direct means of investigating intraocular autonomic integrity, whilst reflex 


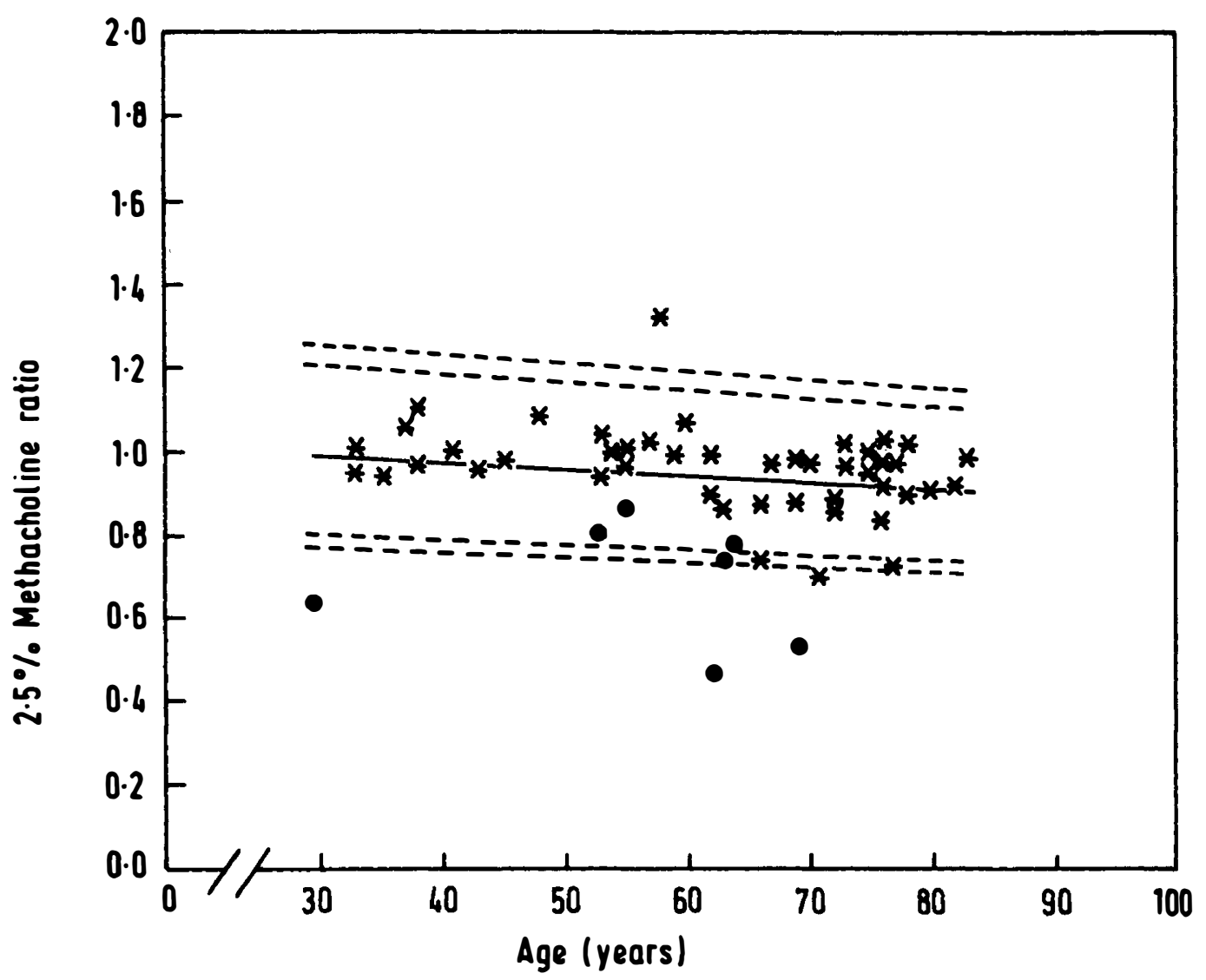

\section{- = LEMS patients}

$*=$ Control subjects

Fig. 2. Age-adjusted normal tolerance intervals for $2.5 \%$ methacholine ratio: mean, and the 90 th and 95 th percentiles of the log normal distribution (hatched line) are shown.

production of tears is a less sensitive measure of extraocular autonomic nerve function. Pupillary response to light is a well-recognised test of the pupillary reflex arc. ${ }^{12}$ There are three types of pupillary movement in controlled lighting conditions:

(i) Hippus

This is defined as a physiological pupillary unrest in stable lighting conditions, and is characterised by a continuous irregularity of pupil movement of variable amplitude. ${ }^{19,20}$ (ii) Pupillary oscillation in drowsy subjects Characteristics features of this pupil movement include variable amplitude, episodic regularity, extended cycle time, and persistence even in the absence of light. ${ }^{21,22}$ (iii) Pupil cycle time

Regular pupillary oscillations are induced reflexly by illumination of the pupil margin with a thin beam of light. Stark and Cornsweet $^{23}$ applied a servo-analytic hypothesis to explain the pupillary oscillation in response to edge-light illumination, concluding that the phenomenon was a manifestation of the pupillary reflex arc. Pupil cycle time assesses the integrity of the complete reflex pathway. It has been used as an objective measure of the defect in patients with lesions of the afferent limb; pupil cycle time, for example, is significantly prolonged in patients with optic nerve compression from chiasmal tumours or Graves' disease, ${ }^{24}$ optic neuritis ${ }^{25}$ and retro- 


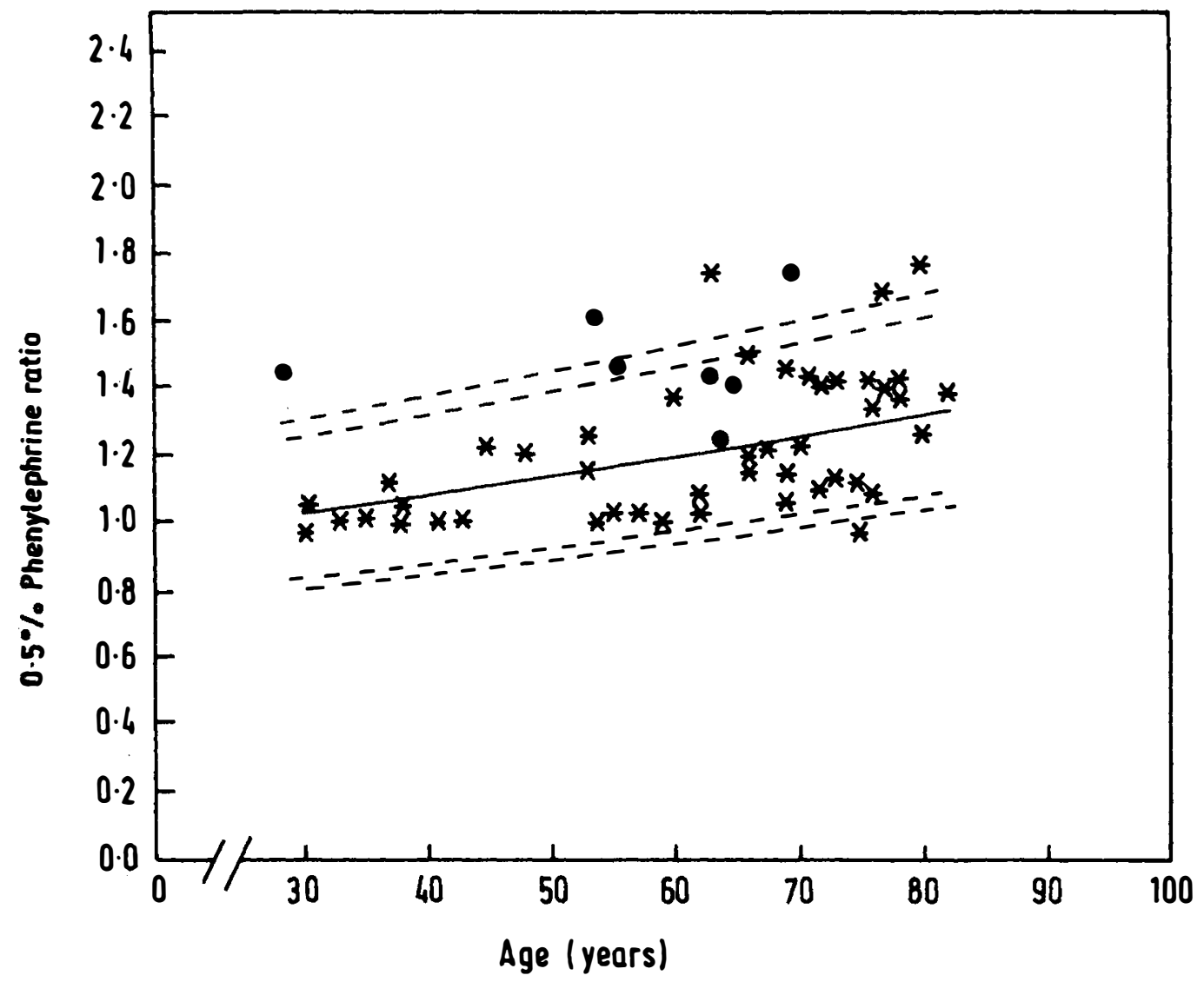

\section{- = LEMS patients} * = Control subjects

Fig. 3. Age-adjusted normal tolerance intervals for $0.5 \%$ phenylephrine ratio: mean, and the 90 th and 95 th percentiles of the log normal distribution (hatched line) are shown.

bulbar neuritis. ${ }^{26}$ Similarly, pupil cycle time has been proposed as a particularly sensitive measure of dysfunction in the parasympathetic efferent limb of the pupillary reflex arc. ${ }^{27}$ Precise anatomical localisation of defects in pupillary function requires specific tests to assess individually the efficacy of autonomic innervation to the sphincter and dilator pupillae muscles in the anterior segment. In the presence of significant neuropathy, one may assume that an intact effector tissue will exhibit hypersensitive responses to topically applied chemical neurotransmitters-the principle of denervation hypersensitivity. Thus pupil cycle time is a relatively non-specific screening test of the integrity of the pupil- lary reflex arc; in the presence of an intact afferent limb, inferences regarding the parasympathetic efferent limb may reasonably be drawn. As this test is rapid, non-invasive, and involves no discomfort to the patient, it is therefore particularly suitable for clinical application as a screening procedure. Investigation of abnormal results in pupil cycling may then be more thoroughly examined by assessment of denervation hypersensitivity, which provides a specific measure of parasympathetic and sympathetic efficacy.

The present study has demonstrated distinctive changes in the ocular function of patients with LEMS, specifically related to autonomic innervation of the eye and ocular 
adnexae. Visual acuity, colour vision, visual fields, intraocular pressure, retinal nerve fibre layer and retinal vasculature were normal in all eyes of LEMS patients. A minimal degree of ptosis was present in two patients: however extraocular movements were predominantly normal, the only significant features being slow saccades in one subject and minimal diplopia on extreme abduction in another. These results accord with accepted extraocular features of LEMS, where a mild ptosis may be present; overt diplopia, however, is rare. ${ }^{2}$ By contrast, significant abnormalities in ocular autonomic nerve function were present in every LEMS patient, with pupillary dysfunction and/or abnormal tear production. Ocular autonomic abnormalities were symmetrical, a characteristic feature of symptoms and signs in LEMS. ${ }^{2}$ Pupil responses to light, assessed by measurement of the pupil cycle time, were abnormal in $69 \%$ of eyes from LEMS patients; reflex tear production, under the control of the parasympathetic nervous system, was similarly abnormal in $69 \%$ of LEMS eyes; and both parasympathetic and sympathetic denervation hypersensitivity of the iris were separately present in $57 \%$ of LEMS patients. There were no significant differences between the degree of ocular autonomic dysfunction in carcinoma-associated and non-carcinoma-associated LEMS, although this must be viewed in the context of only seven patients.

The apparent evidence of involvement of sympathetic as well as parasympathetic function is of special interest. The effects of LEMS IgG on acetylcholine release from motor nerve terminals is exerted by down-regulation of presynaptic voltage gated $\mathrm{Ca}^{2+}$ channels probably by cross-linking of the channels by anti- $\mathrm{Ca}^{2}+$ channel antibodies. ${ }^{28}$ One may speculate that the autonomic effects observed in the present study are similarly exerted by anti-Ca ${ }^{2}+$ channel antibodies, but their site(s) of action are presently unknown.

\footnotetext{
References

${ }^{1}$ Lambert EH and Rooke ED: Myasthenic state and Lung Cancer. Inc: Brain L, Norris F, eds. The remote effects of cancer on the nervous system. Contemporary neurology symposia. New York: Brune and Stratton Ind 1965: 67-80.

${ }^{2}$ O'Neill JH, Murray NMF, Newsom-Davis J: The Lambert-Eaton Myasthenic Syndrome: a review of 50 cases. Brain, 1988, 111: 577-96.
}

${ }^{3}$ Lang B, Newsom-Davis J, W-Wray D, Vincent A, Murray N: Autoimmune aetiology for myasthenic (Lambert-Eaton) syndrome. Lancet 1981, ii: 224-6.

${ }^{4}$ Fukunaga H, Engel AG, Osame M, Lambert EH: Paucity of presynaptic membrane active zones in the Lambert-Eaton myasthenic syndrome revealed by freeze fracture electron microscopy. Neurology (NY) 1982, 32: A222.

${ }^{5}$ Lang B, Newsom-Davis J, Prior C, W-Wray D: Antibodies to motor nerve terminals: an electrophysiological study of a human myasthenic syndrome transferred to mouse. J Physiol (Lond), 1983, 344: $335-45$.

${ }^{6}$ Lang B, Newsom-Davis J, Peers C, Prior C, W-Wray D: The effect of myasthenic syndrome antibody on presynaptic calcium channels in the mouse. $J$ Physiol (Lond), 1987, 390: 257-70.

${ }^{7}$ Fukunaga $\mathrm{H}$, Engel AG, Lang B, Newsom-Davis J, Vincent A: Passive transfer to Lambert-Eaton myasthenic syndrome with IgG from man to mouse depleted the presynaptic membrane active zones. Proc Nat Acad Sci, USA 1983, 80: 7636-40.

${ }^{8}$ Roberts A, Perera S, Lang B, Vincent A, NewsomDavis J: Paraneoplastic myasthenic syndrome IgG inhibits ${ }^{45} \mathrm{CA}^{2+}$ flux in a human small cell carcinoma line. Nature, 1985, 317: 737-9.

${ }^{9}$ Rubenstein AE, Horowitz SH, Bender AN: Cholinergic dysautonomia and Eaton-Lambert Syndrome. Neurology 1979, 29: 720-3.

${ }^{10}$ Khurana RK, Koski CL, Mayer RF: Dysautonomia in Eaton-Lambert syndrome. Ann Neurol 1983, 14: 123.

${ }^{11}$ Mamdami MB, Walsh RL, Rubino FA, Brannegan RT, Hwang MH: Autonomic dysfunction and Eaton-Lambert syndrome. J Aut Nerv Syst 1985, 12: 315-20.

${ }^{12}$ Miller SD and Thompson HS: Edge-light pupil cycle time. Br J Ophthalmol 1978, 62: 495-500.

${ }^{13}$ Scheie HG: Site of disturbance in Adie's syndrome. Arch Ophthalmol 1940, 24: 225-37.

${ }^{14}$ Clark CV and Mapstone R: Parasympathetic denervation hypersensitivity of the iris in ocular hypertension. Invest Ophthalmol Vis Sci 1987, 28: 1732-34.

${ }^{15}$ Clark CV: Ocular autonomic nerve function in proliferative diabetic retinopathy. Eye 1988, 2: 96-101.

${ }^{16}$ Newell FW: Ophthalmology principles and concepts. 5th ed St Louis: CV Mosby Co 1982, 45.

${ }^{17}$ Newell FW: Ophthalmology principles and concepts. 5th ed St Louis: CV Mosby Co 1982, 226.

${ }^{18}$ Clark CV and Mapstone R: Pupil cycle time in primary closed-angle glaucoma. Can J Ophthalmol 1986, 21: 88-91.

${ }^{19}$ Thompson HS: Hippus Arch Internal Med 1969, 123: 598.

${ }^{20}$ Thompson HS, Franceschetti AT, Thompson PM: Hippus. Semantic and historic considerations of the word. Am J Ophthalmol 1971, 17: 1116-120.

${ }^{21}$ Lowenstein O, Feinberg R, Loewenfeld IE: Pupillary movements during acute and chronic fatigue. Invest Ophthalmol 1963, 2: 138-57.

${ }^{22}$ Yoss RE, Mayer N J, Hollenhorst RW: Pupil size and spontaneous pupillary waves associated with 
alertness, drowsiness and sleep. Neurology 1970; 20: $545-54$.

${ }^{23}$ Stark L and Cornsweet T: Testing a servoanalytic hypothesis for pupil oscillation. Science 1958, 127: 588.

${ }^{24}$ Weinstein JM, Van Gilder JC, Thompson HS: Pupil cycle time in optic nerve compression. Am JOphthalmol 1980, 89: 263-7.

${ }^{25}$ Ukai K, Higashi JT, Ishikawa S: Edge-light pupil oscillation of optic neuritis. Neuro-ophthalmol 1980, 1: 33-43.
${ }^{26}$ Cox TA, Thompson HS, Hayreh SS, Snyder JE: Visual evoked potential and pupillary signs. Arch Ophthalmol 1982, 100: 1603-7.

${ }^{27}$ Martyn CN and Ewing D J: Pupil cycle time: a simple way of measuring an autonomic reflex $J$ Neurol Neurosurg Psychiat 1986, 49: 771-4.

${ }^{28}$ Fukuoka T, Engel AG, Lang B, Newsom-Davis J, Prior C, W-Wray D: Lambert-Eaton myasthenic syndrome. 1. Early morphologic effects of Ig C on the presynaptic membrane active zones. Ann Neurol, 1987, 22: 193-9. 